\title{
Inserção da Família nas Salas de Recursos Multifuncionais: uma revisão sistemática de literatura
}

\section{Family insertion in the routine of the Multifunctional Resources Rooms: a systematic literature review}

\author{
Cleomar Lima Pereira ${ }^{1 *}$, Ginia Kenia Machado $\mathrm{Maia}^{2}$, Elisangela Rodrigues Costa ${ }^{3}$, Nando \\ Marley Lima Pacheco ${ }^{4}$, Lívia da Conceição Costa Zaqueu ${ }^{5}$
}

\begin{abstract}
RESUMO
Este trabalho teve como objetivo realizar uma revisão sistemática de literatura sobre a inserção da família nas Salas de Recursos Multifuncionais (SRM). A pesquisa foi feita tendo como base o resumo dos trabalhos publicados no portal de periódicos da CAPES no período de 2015 a 2018. Como critério de busca utilizouse os descritores "família", "inclusão", "atendimento educacional especializado" e "sala de recursos multifuncionais". Os resultados indicaram que as pesquisas que tratam da família na perspectiva da educação inclusiva apontam para a importância do estreitamento da relação família-escola, no entanto não apresentam propostas mais práticas. As pesquisas apresentam o anseio por ações colaborativas entre os atores envolvidos no processo de inclusão. Constatou-se a escassez de trabalhos voltados para a participação da família nas rotinas do atendimento educacional especializado (AEE) nas Salas de Recursos.
\end{abstract}

Palavras-chave: Família; Inclusão; Atendimento Educacional Especializado; Sala de Recursos Multifuncionais.

\begin{abstract}
This article realized a systematic review of the literature on the insertion of the family in the routine of the Multifunctional Resource Rooms (SRM) from a reflective look on the Specialized Educational Assistance in Brazil. Research conducted based on the summary of the works published in the periodical portal of CAPES from 2015 to 2018. As search criterion the descriptors "family", "inclusion", "specialized educational service" and "multifunctional resources room" were used. The results indicated that research that deals with the family in the perspective of inclusive education points to the importance of the closer family-school relationship but does not present more practical proposals. The research show the wish for collaborative actions among the actors involved in the inclusion process. It was verified the shortage of works aimed at the insertion of the family in the routines of the specialized educational (AEE) service in the rooms of multifunctional resources.
\end{abstract}

Keywords: Family; Inclusion; Specialized Educational Attendance; Multifunctional Resource Room.

\footnotetext{
${ }^{1}$ Professora do Instituto Federal do Maranhão. *E-mail: cleomar.lima@ifma.edu.br

${ }^{2}$ Professora da Secretaria Municipal de Educação de São Luís -MA

3 Pedagoga do Núcleo de Educação à Distância da Universidade Federal do Maranhão

${ }^{4}$ Mestrando do PPGEEB da Universidade Federal do Maranhão

5 Professora do PPGEEB da Universidade Federal do Maranhão
} 


\section{INTRODUÇÃO}

A família é a primeira instituição social na qual o indivíduo terá contato, sendo nela, portanto, o primeiro impacto decorrente da descoberta da deficiência (FIAMENGHI, 2007). Nesse momento, a relação familiar é marcada por conflitos psicológicos de negação, luto e desconstrução das expectativas elaboradas durante a gestação (FIAMENGHI, 2007).

Estudos como o de Franco (2015); Soares (2012); Fiamenghi (2007) Maciel (2000) demonstram que a participação da família em grupos de intervenção ou programas que os auxiliem com seus filhos com deficiência é de extrema importância para o não adoecimento de ambos (pais/responsáveis e filhos). Fortalecê-la é vislumbrar um processo inclusivo com mais qualidade, haja vista que a inclusão familiar é decisiva para todos os momentos da vida de quem possui deficiência, é pela família que começa a inclusão (FRANCO, 2015)

O exposto demonstra a relevância da inserção da família no processo educacional de estudantes com deficiência, e como essa ação pode impactar positivamente na vida destes. Como enfatiza Fiamenghi (2007, p.239) “o lugar da criança é determinado pelas expectativas que os progenitores têm sobre ela", o que se reflete também no âmbito escolar. As implicações educacionais, positivas ou negativas, são também geradas pelo apoio e conhecimento adquirido pelas famílias (FRANCO, 2015).

A Declaração de Salamanca (BRASIL,1994) nos aponta que o processo educativo é uma tarefa a ser dividida entre a família e os profissionais, que uma atitude positiva da parte dos pais favorece a integração escolar e social. Sinaliza que para tanto pais necessitam de apoio para que possam assumir seus papéis de pais de uma criança com necessidades especiais (BRASIL, 1994).

Compreendemos que a participação da família nos processos educativos é decisiva para o desenvolvimento dos indivíduos na sua integralidade. A Lei de Diretrizes e Bases da Educação Brasileira, no 9.394/96, define a família como corresponsável pela educação dos indivíduos e aponta que os docentes poderão colaborar com as atividades de articulação da escola com a família (BRASIL, 1996).

Na perspectiva da Educação Inclusiva a Política Nacional de Educação Especial (BRASIL, 2008, p. 14) em seu objetivo destaca a participação e orientação da família 
para assegurar a inclusão escolar de alunos com deficiência, transtornos globais do desenvolvimento e altas habilidades/superdotação.

As Diretrizes apresentadas na Política de Educação Especial aponta o Atendimento Educacional Especializado (AEE), como um serviço complementar ou suplementar a formação dos alunos com vistas à autonomia e independência na escola e fora dela (BRASIL, 2008). Define a Política que:

\begin{abstract}
O atendimento educacional especializado identifica, elabora e organiza recursos pedagógicos e de acessibilidade que eliminem as barreiras para a plena participação dos alunos, considerando as suas necessidades específicas. As atividades desenvolvidas no atendimento educacional especializado diferenciam-se daquelas realizadas na sala de aula comum, não sendo substitutivas à escolarização. (BRASIL, 2008, p.16)
\end{abstract}

Esse atendimento passa a ser organizado pela Resolução nº 04/2009, que institui Diretrizes Operacionais para o AEE na Educação Básica, e o Decreto n 7.611/2011 que dispõe sobre a educação especial, o atendimento educacional especializado e dá outras providências.

Partindo desses pressupostos e do que dispõe o Decreto $\mathrm{n}^{\circ} 7.611$ (BRASIL, 2011), ao expor que "o atendimento educacional especializado deve integrar a proposta pedagógica da escola, envolver a participação da família para garantir pleno acesso e participação os estudantes [...]" (Art. $2^{\circ} \S 2^{\circ}$, grifo nosso), acreditamos que a Sala de Recursos Multifuncionais se constitui como um dos espaços privilegiados para a organização e participação da família e que, portanto, merece destaque em nossas pesquisas.

De forma geral, consideramos que a relação entre família e escola ainda se impõe como um desafio às demandas educacionais, fazendo com que este seja um tema de inquietação e investigação para muitos pesquisadores da educação, nos diferentes níveis e modalidades de ensino. Nessa perspectiva, é que o presente artigo buscou investigar as publicações em educação que versam sobre a inclusão da família no contexto do atendimento educacional especializado nas Salas de Recursos Multifuncionais.

De que forma, os pesquisadores vêm trabalhando a questão da participação da família no espaço escolar? Como as produções científicas abordam a família no processo educacional inclusivo? Família e Sala de Recursos Multifuncionais: que produções e contribuições têm sido realizadas? Estas são questões que norteiam nossa investigação. 


\section{O PERCURSO METODOLÓGICO PARA A REVISÃO DE LITERATURA}

Inserção da Família nas Salas de Recursos Multifuncionais caracteriza-se como uma pesquisa de revisão sistemática de literatura, portanto de caráter exploratório, cujo objetivo consiste em organizar, esclarecer e resumir as principais obras existentes, bem como fornecer citações completas, abrangendo o espectro de literatura relevante em uma área (VOSGERAU e ROMANOWSKI, 2014). Ferreira (2002, p.259) afirma que esse método de pesquisa pretende "conhecer o já construído e produzido para depois buscar o que ainda não foi dito".

Para realização da pesquisa adotamos os seguintes procedimentos:

a) Planejamento: no qual definimos as questões norteadoras da pesquisa, os critérios de inclusão e exclusão e a fonte de busca;

b) Execução: onde foi realizada a seleção dos trabalhos através de busca automática de publicações indexadas na base de dados no Portal de Periódicos da CAPES, sobre a inserção da família nas salas de recursos multifuncionais por meio do Atendimento Educacional Especializado;

c) Análise e resultados: realizada com base na leitura dos resumos e dos dados neles apresentados.

No levantamento realizado na base de periódicos do portal da CAPES encontramos pesquisas relacionadas à família que versam sobre Atendimento Educacional Especializado, Educação Especial e Educação Inclusiva, entre outros. Na pesquisa utilizamos os descritores "Família", "Inclusão", "Atendimento Educacional Especializado" e "Sala de Recursos".

O período de investigação limitou-se aos anos de 2015 a 2018, utilizando-se as pesquisas publicadas em formato de artigos, relacionadas à Educação e publicados em Língua Portuguesa.

A partir da pesquisa realizada, encontramos 14 (quatorze) artigos, os quais foram analisados visando perceber quais das pesquisas encontradas se aproximam do nosso objeto de estudo, bem como perceber como estas pesquisas tratam a participação da família na escola, mais especificamente a inserção dela no espaço da Sala de Recursos Multifuncionais no AEE.

Para a escolha dos artigos foram adotados os seguintes critérios de inclusão e exclusão: 
Quadro 1 - Fatores de inclusão e exclusão de trabalhos

\begin{tabular}{ll}
\hline FATORES DE INCLUSÃO & FATORES DE EXCLUSÃO \\
\hline Artigos disponíveis no portal da CAPES & $\begin{array}{l}\text { Artigos disponíveis em outras bases de } \\
\text { dados }\end{array}$ \\
Publicação no período 2015 a 2018 & Publicações anteriores a 2015 \\
$\begin{array}{l}\text { Artigos que apresentaram os descritores } \\
\text { "Família", "Inclusão", "Atendimento } \\
\text { Educacional Especializado" e "Sala de } \\
\text { Recursos Multifuncionais". }\end{array}$ & $\begin{array}{l}\text { Artigos que não abordaram os descritores } \\
\text { selecionados }\end{array}$ \\
Estudos escritos em Língua Portuguesa & Estudos escritos em outras línguas
\end{tabular}

Fonte: Elaborado pelos autores, 2018.

Mediante as análises iniciais, foram selecionados 8 (oito) artigos que estão sistematizados no Quadro a seguir.

Quadro 2: Relação de trabalhos selecionados

\begin{tabular}{|l|l|c|}
\hline \multicolumn{1}{|c|}{ TÍTULO } & \multicolumn{1}{|c|}{ AUTORIA } & ANO \\
\hline $\begin{array}{l}\text { Atendimento Educacional } \\
\text { Especializado: aspectos da formação do } \\
\text { professor }\end{array}$ & $\begin{array}{l}\text { PASIAN, Mara Silvia; MENDES, } \\
\text { Enicéia Gonçalves; Cia Fabiana } \\
\text { Cadernos de Pesquisa, 2017, } \\
\text { Vol.47(165), pp.964-98 }\end{array}$ & 2017 \\
\hline $\begin{array}{l}\text { O contexto da educação especial na } \\
\text { perspectiva da educação inclusiva: as } \\
\text { vozes dos professores e familiares na } \\
\text { rede municipal de ensino de Joinville } \\
\text { (SC) }\end{array}$ & $\begin{array}{l}\text { FETTBACK, Carin Schultze; } \\
\text { BALDIN, Nelma. Política e } \\
\text { Gestão Educacional, 01 February, } \\
\text { 2017. }\end{array}$ & 2017 \\
\hline $\begin{array}{l}\text { Envolvimento parental e a inclusão de } \\
\text { alunos com autismo }\end{array}$ & $\begin{array}{l}\text { VARGAS, Rosanita Moschini; } \\
\text { SCHMIDT, Carlos. Acta } \\
\text { Scientiarum. Education, 2017, } \\
\text { Vol.39(2), pp.207-217. }\end{array}$ & 2017 \\
\hline $\begin{array}{l}\text { Trabalho docente com alunos público da } \\
\text { educação especial na educação infantil }\end{array}$ & $\begin{array}{l}\text { MARQUES, Jaqueline Belga; } \\
\text { GIROTO; Claudia Regina Mosca. } \\
\text { Revista Ibero-Americana de } \\
\text { Estudos em Educação, 01 } \\
\text { September 2016, Vol.11(2esp), } \\
\text { pp.895-910. }\end{array}$ & 2016 \\
\hline $\begin{array}{l}\text { A relação entre o professor da educação } \\
\text { especial e da educação comum }\end{array}$ & $\begin{array}{l}\text { MIRANDA, Theresinha } \\
\text { Guimarães. Journal of Research in }\end{array}$ & 2016 \\
\hline
\end{tabular}




\begin{tabular}{|l|l|c|}
\hline & $\begin{array}{l}\text { Special Educational Needs, } \\
\text { August 2016, Vol.16, pp.98-105. }\end{array}$ & \\
\hline $\begin{array}{l}\text { Abordagem relacional entre família e } \\
\text { escola inclusiva sob as perspectivas de } \\
\text { professores }\end{array}$ & $\begin{array}{l}\text { SILVA, Aline Maira da; } \\
\text { CABRAL, Leonardo Santos } \\
\text { Amâncio; MARTINS, Morgana } \\
\text { de Fátima Agostini. Interfaces da } \\
\text { Educação, 01 June 2016, } \\
\text { Vol.7(19), pp.191-205. }\end{array}$ & 2016 \\
\hline $\begin{array}{l}\text { Relação família e escola no contexto da } \\
\text { inclusão: opinião de professores pré- } \\
\text { escolares. }\end{array}$ & $\begin{array}{l}\text { BORGES, Laura; GUALDA, } \\
\text { Danielli Silva; Cia Fabiana. }\end{array}$ & 2015 \\
& $\begin{array}{l}\text { Educação: Teoria e Prática, 01 } \\
\text { April 2015, Vol.25(48), pp.168- } \\
\text { 185. }\end{array}$ & \\
\hline $\begin{array}{l}\text { Interdependência na figuração família- } \\
\text { escola na inclusão do estudante com } \\
\text { deficiência }\end{array}$ & $\begin{array}{l}\text { PANTALEÃO, Edson; GOMES, } \\
\text { Núbia Rosetti Nascimento; } \\
\text { CARVALHO Elaine. Critica } \\
\text { Educativa, 01 December 2015, } \\
\text { Vol.1(2), pp.66-81. }\end{array}$ & 2015 \\
\hline
\end{tabular}

Fonte: Elaborado pelos autores, 2018.

\section{UMA VISÃO GERAL DAS PESQUISAS ENCONTRADAS}

Um dos grandes desafios na realização da revisão de literatura é a síntese de dados. Brandão et al (1986, p. 7) utiliza a expressão "estado do conhecimento" para explicitar o processo de revisão de literatura como sendo "levantamentos do que se conhece sobre um determinado assunto a partir das pesquisas realizadas em uma determinada área”.

Para Vosgerau e Romanowski (2014) um estado do conhecimento não se restringe a identificar a produção, mas analisá-la, categorizá-la e revelar os múltiplos enfoques e perspectivas.

Assim, procedeu-se a análise dos resumos dos trabalhos selecionados iniciando com a pesquisa de Pasian e Mendes (2017) sobre o Atendimento Educacional Especializado (AEE) no qual apresenta aspectos relacionados à formação do professor para esse atendimento nas salas de recursos multifuncionais.

Importante ressaltar que um dos pontos em destaque no que tange às necessidades dos professores foi apontado o reconhecimento da participação da família nesse contexto. 
Em: o contexto da educação especial na perspectiva da educação inclusiva: as vozes dos professores e familiares na rede municipal de ensino de Joinville (SC), as autoras (FETTBACK e BALDIN, 2017) discutem a aplicabilidade da política de educação especial na perspectiva da inclusão, objetivando compreender como se dá a relação entre a escola, a família e o Atendimento Educacional Especializado. A pesquisa foi realizada com pais e professores para analisar os dizeres destes em relação ao AEE. Constatou-se na pesquisa desconhecimento dos pais e dos professores da sala comum sobre o serviço realizado.

A pesquisa sobre Envolvimento parental e a inclusão de alunos com autismo, realizada por Vargas e Schmidt (2017), caracteriza o Transtorno do Espectro Autista (TEA) explicitando que as dificuldades apresentadas por este transtorno muitas vezes contribuem para o isolamento das crianças e de seus pais, inclusive da escola. Essa realidade reflete a necessidade de uma aproximação entre os contextos familiar e escolar como um dispositivo de desenvolvimento e aprendizagem. "O Envolvimento Parental se refere às práticas educativas que os pais desenvolvem em relação aos filhos, incluindo o envolvimento com a escola".

No Trabalho docente com alunos público-alvo na educação especial na educação infantil (MARQUES e GIROTO, 2016) a realização da pesquisa teve como objetivo investigar a prática do professor com alunos com Transtorno do Espectro Autista (TEA) onde se verificou barreiras atitudinais e a dificuldade de compreensões conceituais, constatando-se a necessidade de práticas colaborativas entre professores da sala comum, da sala de recursos multifuncionais e da família.

Miranda (2016) pauta sua pesquisa “a relação entre o professor da educação especial e da educação comum" no impacto das ações colaborativas para a promoção da inclusão e destaca que ser fundamental a criação de condições necessárias na escola para a prática da articulação entre esses dois grupos de docentes, para que o trabalho pedagógico seja desenvolvido como parte da gestão escolar e da relação com a família.

Pesquisa realizada em escolas municipais de Dourado/MS para ouvir os professores (19) sobre a relação entre escola e família do aluno com deficiência.

A pesquisa demonstrou que há parceria, contudo evidencia "a necessidade de se fomentar o estabelecimento de uma relação mais efetiva e colaborativa entre os profissionais da escola e os membros familiares". Os pesquisadores (SILVA e CABRAL, 
2016) ressaltam que é preciso possibilitar aos familiares o acesso a informações sobre seus direitos, responsabilidades e recursos.

Com objetivo de avaliar a relação entre a família e a escola considerando o processo de inclusão, Borges e Gualda (2015) destacaram em seu trabalho a opinião dos professores pré-escolares sobre:

a) o principal fator que influência o sucesso das crianças;

b) como é realizada a relação da escola com a família;

c) quais estratégias são utilizadas para a comunicação com a família;

d) qual a relação dos professores com a família.

Mediante o resultado apresentado a partir das respostas levantadas, as autoras (BORGES e GUALDA, 2015) constataram "a necessidade de intervenção com pais e professores para estreitar a relação entre eles, a fim de que possam favorecer o desenvolvimento e a aprendizagem da criança pré-escolar incluída”.

O trabalho etnográfico, Interdependência na figuração família-escola na inclusão do estudante com deficiência, dos pesquisadores Pantaleão, Gomes e Carvalho (2015), apresenta os dilemas e perspectivas na relação família e escola, retratados por meio das falas dos pais/familiares de estudantes com deficiência e dos profissionais que atuam nas Secretarias de Educação e nas escolas.

As falas apresentadas convergem para a valorização dessa relação, entretanto ainda se apresenta um isolamento de ambas, concluem o trabalho identificando que "a superação da exclusão escolar pode ser construída atrelada às transformações dessas relações e da sociedade".

\section{ANÁLISE SOBRE A INSERÇÃO DA FAMÍLIA NAS SALAS DE RECURSOS MULTIFUNCIONAIS}

A partir das questões que nortearam nosso olhar na análise dos trabalhos categorizados foi possível estabelecer algumas hipóteses e reflexões. De que forma, os pesquisadores vêm trabalhando a questão da participação da família no espaço escolar? Como as produções científicas abordam a família no processo educacional inclusivo? Família e Sala de Recursos Multifuncionais: que produções e contribuições têm sido realizadas? 
Falar de família numa perspectiva inclusiva nos remete antes de tudo aos princípios de universalização de direitos, entre eles ao de acesso a educação de oportunidades e de equidade, orientadas por instrumentos legais nacionais e internacionais (SALAMANCA, 1994; LBDEN, 1996; BRASIL, 2008).

É neste contexto que todos os trabalhos selecionados justificam suas pesquisas e contribuições para o processo de ensino e de aprendizagem para os alunos público-alvo da educação especial. Assim, buscou-se também observar como a família tendo sido inserida nesse processo e nas pesquisas em destaque. No entendimento de Glat (2012) para que toda criança deficiente seja integrada na sociedade, antes ela necessita de ser integrada em sua própria família.

De forma geral, as pesquisas sempre apontam para a necessidade de fortalecer a relação família e escola, mas não aprofundam a questão ou apresentam possibilidades de inserção desta instituição nas práticas educativas. Glat $(2012$, p.112) relata que "a importância da Família na integração da pessoa com deficiência nem sempre recebe em nossas discussões acadêmicas e nas propostas de atendimento o papel de destaque que merece".

Evidenciamos que de certa maneira a autora (GLAT, 2012) constata uma realidade em relação à participação mais efetiva dos pais/responsáveis no processo educacional ao observarmos a escassez de trabalhos voltados a essa temática, especialmente no que tange a inserção da família nas estratégias metodológicas utilizadas por professores como prática colaborativa. Na busca pelo estado da arte, realizada a partir desse artigo, essa realidade se tornou perceptível.

Esse panorama responde, de certa maneira, nossa primeira questão norteadora sobre como os pesquisadores vêm trabalhando a questão da participação da família no espaço escolar, num papel, quase sempre, de segundo plano, mesmo que haja sempre a ênfase em relação a sua importância.

Para responder como as produções científicas abordam a família no processo educacional inclusivo, nos utilizamos de Rosa (2005) que ressalta ao estudar a história da participação da família nos processos terapêuticos que a família ficou em segundo plano, servindo apenas como informante e que o cuidado era ação exclusiva dos profissionais especializados. Caberia à família se colocar em posição passiva, no aguardo dos resultados das intervenções realizadas pelos detentores do saber competente (ROSA, 2005). 
Fettback e Baldin (2017) deixam clara a afirmação da autora quando ao ouvir as falas dos pais/responsáveis sobre a escola e o Atendimento Educacional Especializado destinado aos seus filhos concluíram que, estes sabem pouco sobre esses serviços. Em contrapartida, a pesquisa sobre o envolvimento parental e a inclusão de alunos com autismo, realizada por Vargas e Schmidt (2017), nos faz perceber que dependendo do grau de dificuldades em relação ao aluno da educação especial a aproximação (parceria) com a família pode acontecer com mais frequência. Nesta experiência foi possível identificar ações colaborativas entre os professores e família.

As ações colaborativas foram evidenciadas e aprofundadas no trabalho docente com alunos público-alvo na educação especial na educação infantil (MARQUES e GIROTO, 2016). Daremos um destaque a esse aspecto visto que nossa área de estudo, pesquisa e intervenção visa à construção de propostas metodológicas colaborativas que possibilitem a inserção das famílias na rotina do AEE nas Salas de Recursos Multifuncionais.

Sobre a ação colaborativa Marques e Giroto (2016, p.905) nos lembram de que "a atuação colaborativa se coaduna com o caráter de suporte mais recentemente atribuído a Educação Especial na perspectiva da educação inclusiva", ressaltando o envolvimento de todos os responsáveis pelo processo de escolarização dos estudantes, em que a família também ocupa lugar de protagonista. Os professores envolvidos na referida pesquisa apontam que é preciso ampliar a participação e colaboração da família, visto que a consideram participativa e preocupada com o desenvolvimento dos seus filhos.

Nos trabalhos selecionados, os resultados apresentados impulsionam a continuidade do estudo na área, visto que em relação à questão: família e Sala de Recursos Multifuncionais: que produções e contribuições têm sido realizadas constatamos a inexistência de produções diretamente vinculadas a esta relação. Ressaltamos ainda que em todas as conclusões se verificou o anseio de professores e pesquisadores em desenvolver propostas que viabilize a inserção da família nos diversos projetos pedagógicos da escola, de forma colaborativa.

\section{CONSIDERAÇÕES FINAIS}


A presente pesquisa de revisão de literatura teve como objetivo sistematizar e analisar as pesquisas publicadas no período de 2015 a 2018 sobre família, inclusão e sala de recursos multifuncionais.

Os resultados indicaram que as pesquisas que tratam da família na perspectiva da educação inclusiva apontam para a importância do estreitamento da relação famíliaescola, no entanto não apresentam propostas mais práticas.

O estudo revelou que pouco são os estudos que investigam a participação das famílias nas salas de recursos multifuncionais por meio do Atendimento Educacional Especializado. E constatamos que as ações colaborativas refletem o anseio de todos os profissionais que estão envolvidos com a inclusão de alunos público-alvo da Educação Especial, inclusive da família.

Concluímos, portanto, que o estudo acerca da temática ainda pode ser ampliado e aprofundado de forma que se possa investigar também comparar as publicações fora do Brasil em contraposição às realizadas no país.

\section{REFERÊNCIAS}

BORGES, Laura; GUALDA, Danielli Silva. relação família e escola no contexto da inclusão: opinião de professores pré-escolares. Cia Fabiana. Educação: Teoria e Prática, 01 April 2015, vol.25(48), pp.168-185.

BRANDÃO et. al.1986, p. 7. Tipos de revisão de literatura. Disponível em: http://www.fca.unesp.br/Home/Biblioteca/tipos-de-evisao-de-literatura.pdf. Acesso em 20/10/2018.

BRASIL. Constituição (1998). Constituição da República Federativa do Brasil. Brasília, DF: Senado, 1988.

BRASIL. Ministério da Ação Social. Coordenadoria Nacional Para Pessoa Portadora de Deficiência. Declaração de Salamanca e linha de ação sobre necessidades educativas especiais. Brasília, DF, 1994. 54 p.149-160.

BRASIL. Lei de Diretrizes e Bases da Educação. Lei n 9.394/96, de 20 de dezembro de 1996.

BRASIL. Política Nacional de Educação Especial na Perspectiva da Educação Inclusiva, 2008.

BRASIL. Decreto 7.611 de 17 de novembro de 2011. Disponível em: http://www.planalto.gov.br/ccivil_03/_ato2011-2014/2011/decreto/d7611.htm

FERREIRA, Norma Sandra de Almeida. As pesquisas denominadas "Estado da Arte". Educação \& Sociedade, ano XXIII, n. 79, agosto/2002, p.257-272. 
FETTBACK , Carin Schultze; BALDIN, Nelma. O contexto da educação especial na perspectiva da educação inclusiva: as vozes dos professores e familiares na rede municipal de ensino de Joinville (SC). Política e Gestão Educacional, 01 February, 2017

FIAMENGHI J. R. G.; MESSA, A. A. Pais, filhos e deficiência: estudos sobre as relações familiares. Psicologia Ciência e Profissão, 27 (2), 236-245. 2007.

FRANCO, Victor. Introdução à intervenção precoce no desenvolvimento da criança com a família, na comunidade, em equipe. Edições Aloendro, 2015.

GLAT, Rosana. O papel da Familia na integração do portador de deficiência. Revista Brasileira de Educação Especial. Disponível em:

http://www.abpee.net/homepageabpee04_06/artigos_em_pdf/revista4numero1pdf/r4_art 09.pdf. Acesso em 20/10/2018.

GLAT, Rosana. Orientação familiar como estratégia facilitadora do desenvolvimento e inclusão de pessoas com necessidades especiais. In: MENDES, E. G. \& ALMEIDA, M. A. (Org) A pesquisa sobre inclusão escolar em suas múltiplas dimensões: teoria, política e formação. Marília: ABPEE, p. 315-326, 2012.

MACIEL, Maria Regina Cazzaniga. Portadores de deficiência: a questão da inclusão social. São Paulo: Perspectiva, vol.14 nº 2 São Paulo Apr. /June 2000.

MARQUES, Jaqueline Belga; GIROTO; MOSCA, Claudia Regina. Trabalho docente com alunos público da educação especial na educação infantil. Revista IberoAmericana de Estudos em Educação, 01 September 2016, Vol.11(2esp), pp.895-910.

MIRANDA, Theresinha Guimarães. A relação entre o professor da educação especial e da educação comum. Journal of Research in Special Educational Needs, August, 2016, Vol.16, pp.98-105.

PANTALEÃO, Edson; GOMES, Núbia Rosetti Nascimento; CARVALHO Elaine. Interdependência na figuração família-escola na inclusão do estudante com deficiência Crítica Educativa, 01 December 2015, Vol.1(2), pp.66-81.

PASIAN, Mara Silvia; MENDES, Enicéia Gonçalves. Atendimento Educacional Especializado: aspectos da formação do professor. Cadernos de Pesquisa, 2017, Vol.47(165), pp.964-98.

ROSA, Lucia Cristina dos Santos. A inclusão da família nos projetos terapêuticosdos serviços de saúde mental. Psicologia em Revista, Belo Horizonte, v. 11, n. 18, p. 205218, dez. 2005.

SILVA, Aline Maira da; CABRAL, Leonardo Santos Amâncio; MARTINS, Morgana de Fátima Agostini. Abordagem relacional entre família e escola inclusiva sob as perspectivas de professores. Interfaces da Educação, 01 June 2016, Vol.7(19), pp.191-205.

VARGAS, Rosanita Moschini; SCHMIDT, Carlos. Acta Scientiarum. Envolvimento parental e a inclusão de alunos com autismo. Education, 2017, Vol.39(2), pp.207-217. 
VOSGERAU, Dilmeire Sant'Anna Ramos; ROMANOWSKI, Joana Paulin. Estudos de revisão: implicações conceituais e metodológicas. Revista Diálogo Educacional, v.14, n. $41,2014$.

Recebido em: 01/10/2021

Aprovado em: 01/11/2021

Publicado em: 10/11/2021 